\title{
Classificação de seres vivos por alunos de anos iniciais do ensino fundamental: uma proposta de desenvolvimento de habilidades científicas
}

Andréa Inês Goldschmidt

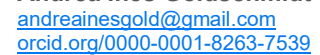
Universidade Federal de Santa Maria (UFSM), Palmeira das Missões, Rio Grande do Sul, Brasil

Ariadne de Freitas Leonardi ariadneleonardi@hotmail.com Universidade Federal de Santa Maria (UFSM), Palmeira das Missões, Rio Grande do Sul, Brasil

\section{Geovane Bernardi} geovanebernardii@gmail.com Uncid.org/0000-0003-2113-1272 (UFSM) Palmeira das Missões, Rio Grande do Sul, Brasil

Sabrina Antunes Ferreira sabrinaantunesferreira@hotmail.com orcid.org/0000-0003-0931-2150 Universidade Federal de Santa Maria (UFSM), Palmeira das Missões, Rio Grande do Sul, Brasil

Maira dos Santos Silveira mairasantossilveira@gmail.com orcid.org/0000-0001-5118-889X Universidade Federal de Santa Maria (UFSM), Palmeira das Missões, Rio Grande do Sul, Brasil

\section{RESUMO}

O artigo apresenta uma experiência pedagógica desenvolvida junto a estudantes de anos iniciais do ensino fundamental de uma escola pública no município de Palmeira das Missões, RS. A experiência foi desenvolvida através da temática "Classificação biológica dos seres vivos" que objetivou a percepção dos estudantes através de seus conhecimentos cotidianos sobre a forma de organização e classificação da diversidade dos organismos vivos, possibilitando avaliar e discutir as diferenças em relação à classificação biológica, sem, contudo, propor a exclusão de um conhecimento por considerar o outro o correto. Além, disso, oportunizar aos alunos no desenvolvimento de habilidades científicas, associadas ao observar, organizar, classificar, propor modelos, argumentar e relatar oralmente. A pesquisa teve como instrumento investigativo a construção em grupos de cartazes, apresentando um sistema de classificação biológica a partir da observação de 36 imagens (fotográficas) contendo diferentes exemplares de animais, vegetais, fungos, vírus, bactérias e protozoários. Os alunos foram observados em cada grupo por um dos pesquisadores e além de organizarem o sistema classificatório, deveriam estabelecer critérios para os mesmos. Ao todo, foram formados dezesseis grupos, que organizaram dezesseis cartazes de classificação, estes foram recolhidos e analisados. Os resultados permitiram evidenciar que os alunos classificaram os animais de acordo com o ambiente em que vivem, táxon, e características observáveis. Verificou-se que a classificação por habitat diminuiu com o avanço dos anos de escolaridade, dando menos ênfase à observação. Quanto às plantas, observou-se que a maioria dos alunos possui uma visão utilitarista antropocêntrica, em especial ao papel destes organismos na alimentação humana. Em relação aos microrganismos notou-se que os alunos possuem uma visão reducionista e muitas vezes errônea referente a esses seres, classificando-os como pequenos causadores de doenças. Ao compararmos os anos de ensino, verificou-se que os alunos dos primeiros anos (primeiro, segundo e terceiro) apresentam uma melhor observação e à medida que possuem mais idade, a classificação foi mais memorística, baseada em táxons e classificações presentes em livros didáticos. Tais resultados mostram que desenvolver as habilidades científicas dos alunos é muito importante.

PALAVRAS-CHAVE: Sistemática. Ensino de Ciências. Concepções prévias. Primeiros Anos. 


\section{INTRODUÇÃO}

A diversidade biológica é um tema que provoca grande fascínio ao homem desde seus primórdios. Encanta tanto alunos, professores ou meros curiosos sobre a vida. Para Mayr (1982, p. 162), a diversidade das espécies "[...] ocupou a mente humana desde que existiram homens".

Aos olhos de um não especialista, esta diversidade pode não expressar a sua real complexidade, frente às múltiplas possibilidades surgidas ao longo da história, que buscavam organizar e classificar as espécies. Nos dias de hoje os taxonomistas pensam a classificação através de um ponto de vista genealógico, ou seja, tentam agrupar as espécies por suas relações de parentesco, mas isso nem sempre foi assim. Na antiguidade, o modo de classificação biológica mais comumente utilizado, era a olho nu; logo as relações evolutivas não eram levadas em consideração.

Foi através das observações e reflexões, que a humanidade foi descobrindo aspectos importantes a respeito dos organismos da natureza (ALVARENGA et al., 2004) e perceberam que poderiam agrupá-los, a fim de compreender a diversidade dos seres vivos e facilitar seu estudo, estabelecendo padrões ou critérios para a classificação que recebeu uma roupagem ao longo da construção da ciência. Assim, foram desenvolvidos distintos critérios de classificação biológica no intuito de dar ordem à diversidade de seres vivos; mas por muito tempo, os pesquisadores seguiram parâmetros filosóficos diferentes.

Ao pensarmos no ensino da classificação, é importante destacar que o sistema de classificação não é utilizado apenas para organizar os organismos vivos, mas para qualquer finalidade a fim de classificar e agrupar; como ir ao supermercado e se deparar com prateleiras dispostas de uma maneira que facilite a procura de um determinado produto, arrumar as roupas no guarda roupa, organizar as prateleiras com copos, xícaras e pratos, separar talheres e uma infinidade de objetos, assim se inserindo uma classificação cotidiana.

Waizbort (2000) afirma que classificar é um procedimento humano e, portanto, deve ser encarado como racional e lógico. Colocar objetos em classes exige toda uma série de operações mentais que ninguém duvida que sejam exclusivos, de uma certa maneira, do ser humano. Lakoff (1987) corrobora, explicando que a relação do indivíduo com o mundo, por si só, gera um sistema de categorização. Parte-se de categorias intermediárias (ex.: cadeira), que se encontram entre categorizações generalistas (ex.: móvel) e específicas (ex.: poltrona), sendo estas mais básicas e, portanto, as primeiras a serem apreendidas e relembradas. Desta forma, o autor afirma que a maior parte dos conhecimentos é organizada nesse nível básico, também conhecido por gênero na nomenclatura biológica.

Segundo Mayr (2008), ao classificar, reunimos em grupos objetos com características em comum com dois objetivos claros. O primeiro está relacionado à obtenção de informações de forma mais ágil e o segundo diz respeito à possibilidade de realizar comparações em posteriores pesquisas. Sendo assim, a classificação apresenta a importância de ser a responsável por criar um sistema de armazenamento de informações essencialmente importante em qualquer 
área. Portanto, para o ensino em ciências, a classificação biológica consiste no método utilizado pelos pesquisadores para separar e organizar a diversidade de organismos vivos; uma tarefa um tanto quanto complexa, devido à grande quantidade de espécies encontradas em nosso planeta.

Do ponto de vista biológico na cultura ocidental, a classificação dos seres vivos teve seu início na antiguidade com Aristóteles (384-322 a.C.), que classificou os animais baseando-se em aspectos do funcionamento de seus corpos (ALVARENGA et al., 2004). Em decorrência da ampla diversidade, o homem necessitou de uma sistemática para realizar a classificação, utilizando características semelhantes nas espécies e/ou até mesmo diferenças entre elas.

Além de Aristóteles, muitos outros filósofos e historiadores naturais também se preocuparam com a classificação das espécies e levantaram diversos questionamentos sobre a variação das mesmas, a origem e o papel funcional da ordenação dos organismos vivos; entre eles, podemos lembrar, Cesalpino, Linneu, Lamarck e Darwin. (MAYR, 1982; AMORIM, 2008; PABÓN-MOURA e GONZALEZ, 2011).

E foi também nesse nível que no século XVIII, o sueco Carl von Linné se baseou para formar o sistema de classificação biológica por hierarquias, amplamente referido no ensino de biologia da atualidade. Criou o que chamamos de Sistemática Clássica, que utiliza de todas as características observadas em um determinado organismo para classificá-lo dentro de categorias. O pesquisador sistematizou a classificação biológica em seu livro Systema Nature, em 1758, estabelecendo um sistema hierárquico de táxons, bem como a nomenclatura binominal. A classe hierárquica maior é o reino, seguindo filo, classe, ordem, família, gênero e espécie (SIMPSON, 1971). Se utilizou, portanto, da construção de um sistema que levasse em consideração as características cotidianas, a partir das quais por generalizações geraram os níveis mais gerais como classe, ordem, reino e etc. e por especificações passou à descrição dos níveis específicos (LAKOFF, 1987).

No entanto, o sistema de classificação sofreu ao longo da história, ajustes taxonômicos e sistemáticos. Lakoff (1987) afirma ainda que é importante a compreensão de outros sistemas de classificação, pois contribuíram no entendimento sobre a diversidade de seres vivos, como por exemplo, os conceitos de evolução das espécies, que com a introdução do sistema cladístico, permitiu a compreensão do sistema de classificação de Lineu como um processo evolutivo, e através da ciência biológica ocidental, este sistema de ensino chegou às escolas, sendo ensinado e estando presente nas descrições apresentadas nos livros didáticos, os estudos de classificação por níveis hierárquicos propostos por Lineu no século XVIII e no Sistema de Cinco Reinos de Robert H. Whittaker da década de 1960 (ROMA; MONTOKANE, 2007).

Diante deste sistema, a espécie passou a ser caracterizada por um grupo de indivíduos que compartilhassem características morfologicamente semelhantes entre si e distintas dos outros, dentro daquilo que ficou conhecido como conceito tipológico ou essencialista de espécie (MAYR, 2008).

A diversidade de organismos e a forma com que a ciência ocidental lidou e lida com ela têm exercido impacto nas salas de aula e na construção do conhecimento de ciências dos nossos alunos. Desta forma, a classificação de organismos vivos também faz parte e deve ser ensinada já desde os anos iniciais 
do Ensino Fundamental, e isto nos faz questionar como os alunos compreendem este sistema e a partir de que concepções devem ser desenvolvidas tal conteúdo.

Krasilchik (2011) afirma que o aprendizado dos alunos sobre o ensino de Biologia tem sido precário, não sendo capaz de ultrapassar os mecanismos de memorização de informações que são muitas vezes irrelevantes e não relacionadas à realidade do aluno. Os alunos se veem obrigados a decorar conceitos e nomes que, na maioria das vezes, são meramente teóricos, distantes da realidade, fazendo com que alunos percam o interesse, ocasionado uma deficiência na aprendizagem (WELKER, 2007).

Em contraponto, outros autores apresentam ideias de aplicação de planos de aula e atividades, com objetivo de motivar e instigar a percepção do aluno aumentando sua compreensão de conceitos relacionados ao tema (AMORIM et al., 1999; AMORIM et al.., 2002; AMORIM, 2008). Para ocorrer esta aproximação científica, o professor, como mediador, deve encontrar estratégias de ensino que estimulem a aprendizagem. Sobre isso, Leite e Esteves (2005) apontam o papel do professor neste processo, sinalizando a importância de se trabalhar estratégias de ensino capazes de facilitar a aprendizagem de tais conceitos e inter-relações pelos seus alunos.

Ao trabalhar a classificação biológica nos anos iniciais, os processos de sistematização e categorização são importantes para a formação de conceitos (LAKOFF, 1987). Para uma introdução científica ser desenvolvida, Santos e Calor (2007) ressaltam a importância de se trabalhar termos e conceitos científicos em sala de aula. O papel do professor é vincular e estabelecer a ligação dos conceitos científicos ao cotidiano, ocorrendo uma mediação e interligação entre os conhecimentos científicos e empíricos, devendo, portanto, tomar conhecimento dos conceitos cotidianos dos alunos (GASPARIN, 2005). Assim, o uso e percepção dos conhecimentos prévios são primordiais na formação dos conceitos, e consequentemente, dos sistemas de categorização e classificação construídos pelos sujeitos.

Santos (2012) relata ser necessário métodos de aprendizagem que tirem os alunos da posição de agentes passivos e os tornem sujeitos atuantes no seu processo de aprendizagem. De acordo com o autor, o aluno precisa se sentir capaz e seguro para aplicar nas organizações os conhecimentos que estão sendo adquiridos em sala de aula, isentando-o da necessidade de viver com a incerteza de tentativa e erro. Trabalhar em sala de aula a capacidade de pensar além da teoria, propor estratégias e/ou modelos e elaborar argumentações, podem ser oportunidades significativas para o raciocínio científico.

A oportunidade que o ensino de ciências tem, de discutir diferentes formas de interpretação da natureza com a identificação de relações de semelhanças e diferenças com modo científico de pensar, é essencial, como cita Baptista (2010) para o fortalecimento do poder de argumentação dos estudantes, o que contribui para desenvolver habilidades científicas, como a exploração, a observação, classificação e a comparação.

A Base Nacional Comum Curricular (2017) traz diversos desafios, entre eles, o de incluir mais investigação no processo de aprendizagem, trabalhar o letramento científico, e também propor uma progressão de aprendizagem com habilidades. A área de Ciências da Natureza tem um compromisso com o desenvolvimento do letramento científico, que envolve a capacidade de 
compreender e interpretar o mundo (natural, social e tecnológico), mas também de transformá-lo com base nos aportes teóricos e processuais das ciências. Nessa perspectiva, é importante a aproximação gradativa aos principais processos, práticas e procedimentos da investigação científica.

Rodrigues e Rodrigues (2018) discutem que o desenvolvimento de conhecimentos científicos, se fazem necessários já desde os primeiros anos de escolarização, desde que sejam respeitadas as habilidades e o desenvolvimento cognitivo da criança.

Para isto, faz-se importante desenvolver práticas em sala de aula, que possibilitem diferentes situações, como observar o mundo a sua volta e fazer perguntas; propor hipóteses, elaborar explicações e/ou modelos; selecionar e construir argumentos com base em evidências, modelos e/ou conhecimentos científicos; organizar e/ou extrapolar conclusões; relatar informações de forma oral, escrita ou multimodal.

Carvalho et al. (1998), afirmam que ao se incentivar a importância da autonomia do aluno no ambiente de aprendizagem, se possibilita também que sejam aumentadas as habilidades da criança em compreender os temas ensinados e os processos de raciocínio envolvidos.

O ensino de classificação nos anos iniciais pode permitir ao aluno a compreensão básica da organização dos grupos de seres vivos, suas características, semelhanças, diferenças, processos evolutivos, comportamentos, relações ecológicas e relações dos outros animais com o homem, contribuindo para a preservação do meio ambiente e valorização da vida; sendo primordial atingir este conhecimento através do desenvolvimento de habilidades científicas.

Neste contexto, o artigo relata uma experiência pedagógica sobre classificação biológica dos seres vivos, com estudantes de anos iniciais do ensino fundamental, em uma escola pública no município de Palmeira das Missões, RS. O objetivo foi investigar os conhecimentos cotidianos dos estudantes sobre a forma de organização e classificação da diversidade dos organismos vivos, possibilitando avaliar e discutir as diferenças em relação à classificação biológica, sem, contudo, propor a exclusão de um conhecimento por considerar o outro o correto. Ainda, oportunizar aos alunos desenvolver habilidades científicas, como a observação, organização, classificação, proposição de modelos e arguição.

\section{TRAJETÓRIA METODOLÓGICA}

A investigação foi realizada com estudantes dos anos iniciais do Ensino Fundamental em uma escola pública do município de Palmeira das Missões, RS. A metodologia envolveu 111 (cento e onze) alunos, integrantes de duas turmas de 2 ano, duas turmas de 3 ㅇ ano, uma turma de 4ㅇ ano e uma turma de 5ㅇ ano, com crianças entre sete a doze anos de idade. A estratégia didática foi realizada em cada uma das turmas participantes, de forma separada. Os alunos foram convidados a participarem da pesquisa, assinando juntamente aos familiares, um termo livre e esclarecido.

A atividade de pesquisa foi elaborada e desenvolvida pelo grupo de pesquisadores, autores deste artigo e que se encontram em formação inicial docente em Ciências Biológicas na Universidade Federal de Santa Maria, Palmeira 
das Missões. Teve a participação, como observadores, de seis professores, responsáveis pelas turmas na escola.

Foram realizadas quatro sessões de atividades, uma para cada ano de ensino. Desta forma, as duas turmas de 2으 e 3ㅇ ano, foram agrupadas em suas sessões subsequentes. Os alunos foram organizados em quatro grupos, tendo em cada um deles, um pesquisador como mediador das atividades. Cada grupo reuniu-se em círculo, ao redor de uma mesa organizada previamente, com o material para desenvolvimento da proposta pedagógica de classificação biológica. O kit fornecido constava de uma cartolina e de um envelope. Inicialmente foi explicado aos participantes, que dentro deste envelope, haviam 36 "cartas" com imagens de seres vivos, que seriam utilizadas para uma atividade que iniciaria num segundo momento. Nas 36 imagens (fotografias) apresentando os seres vivos, foram representados os principais grupos de organismos: vírus, bactérias, fungos, protozoários, animais e vegetais.

Antes de iniciarem, o primeiro momento foi marcado por um diálogo com os alunos sobre a relevância da classificação dos seres vivos e como é importante estudá-los, contribuindo para identificar suas características e a importância ecológica. Para exemplificar o que seria e como seria uma classificação, dialogouse sobre as formas de classificação e organização utilizadas no cotidiano, como a realizada em bibliotecas e as formas de organização em um supermercado, reforçando a importância desse processo para compreensão da diversidade de recursos encontrados nestes locais. E então, indagou-se: Quem já foi a um supermercado? Como estão dispostos os produtos neste estabelecimento? Quais são os motivos que levam os proprietários dos supermercados a agruparem os produtos nas prateleiras? Esta organização favorece ou não?

Para contextualizar a classificação biológica foi explicado aos alunos que os organismos vivos também foram classificados em grupos conforme as suas características, para serem melhor estudados.

No segundo momento, os alunos foram convidados a abrirem o envelope e observar as imagens fornecidas, de modo que pudessem observar a diversidade biológica. Também deveriam discutir no grupo, formas de organizar através de critérios por eles elaborados, um sistema de classificação, agrupando as imagens em categorias que para eles fariam sentido. A classificação biológica espontânea consistiu na distribuição destas 36 imagens de seres vivos, na mesa, para que todos pudessem olhar as imagens e imaginar os respectivos organismos na natureza e no ambiente em que poderiam ser encontrados, levando em consideração se haveria diferenças e/ou semelhanças entre eles. A partir de dado momento, os participantes iniciaram a classificação biológica.

Após, deveriam organizar tal universo de organismos do modo como considerassem pertinente, e fixassem os mesmos em uma cartolina.

Na sequência, os estudantes iniciaram as discussões para definição dos atributos utilizados para a classificação e organização em grupos dos seres vivos, previamente disponibilizados. Estes atributos considerados eram descritos na cartolina, como categorias de classificação. As representações deveriam ser organizadas de acordo com os critérios utilizados pelo grupo, os quais seriam posteriormente apresentados para toda a turma. O mediador em cada grupo, não interferiu na organização, apenas questionava sobre que grupos os participantes conheciam e os critérios que eles estipulavam. 
Após terminar a preparação dos painéis, foram convidados a compartilhar com toda a turma e a justificar quais foram os critérios utilizados para classificar e organizar os seres vivos ilustrados nas representações. O objetivo para a apresentação foi explicitar diferentes modos de classificação e organização que pudessem surgir entre as propostas e oportunizar a arguição e o relato dos alunos diante da diversidade apresentada. O propósito da atividade, era ainda, que percebessem que pode haver formas distintas de classificação, levando-se em consideração diversas possibilidades.

Após, a atividade, os alunos apresentaram seus sistemas de classificação elaborados, e as cartolinas contendo as imagens foram recolhidas, para posterior análise (Figura 1). Foram obtidos um total de dezesseis cartazes construídos, pois em cada turma organizada de acordo com o ano de ensino, foram montados quatro grupos e, portanto, quatro cartazes de sistemas de classificação. Constituiu o corpus de análise, os dezesseis cartazes elaborados pelas turmas de 2o aos 5 ㅇ anos dos anos iniciais.

Figura 1 - Cartazes construídos, representando os sistemas de classificação elaborados por alunos de anos inicias do ensino fundamental
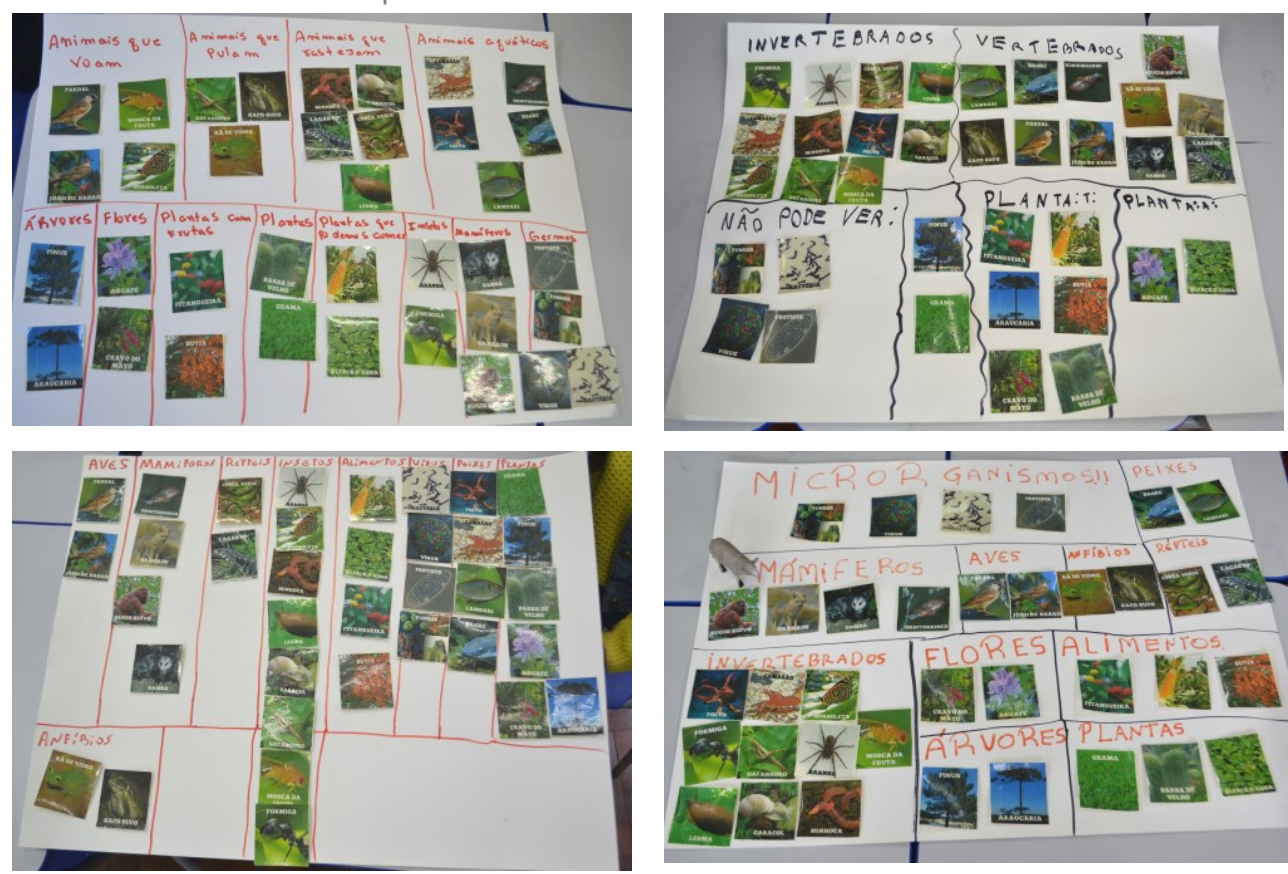

Fonte: Autoria própria (2018).

Para análise da classificação, analisaram-se os cartazes e os critérios de classificação explicitados pelos alunos, de acordo com as categorias e subcategorias elaboradas e escritas para cada subgrupo elaborado e fixado sobre o cartaz. Para tanto, seguiram-se os critérios de classificação de Bardin (2011), no que se refere ao reconhecimento e explicitação de categorias e subcategorias a posteriori. O procedimento inicial implicou na decodificação dos dados contidos nos textos com descrição detalhada das ideias, ou estágio descritivo ou ainda análise categorial.

Os dados foram analisados separadamente (por anos de ensino) e coletivamente, sendo apresentados nas Tabelas 1 a 3, com posterior discussão. 
A análise permitiu verificar como as crianças concebem os sistemas de classificação e se há influência escolar sobre esta organização.

\section{RESULTADOS E DISCUSSÕES}

A análise das informações provenientes dos cartazes de classificação permitiu realizar algumas considerações acerca de como estes alunos elaboram e compreendem um sistema de classificação biológica.

Do total de participantes, $54,55 \%$ eram meninos e $45,45 \%$ meninas, com faixa etária de 7 a 12 anos, de acordo com o nível de ensino, coerente à idade para anos iniciais segundo a legislação.

Mesmo tendo entre as imagens os diferentes grupos de seres vivos, percebeu-se que os alunos de anos iniciais dividiram as figuras em três grupos maiores, partindo de uma observação ampla e generalista: animais, plantas e organismos menores (fusionando todos os demais, que não consideravam animais ou vegetais). Os resultados foram analisados considerando a distribuição proposta pelos estudantes e são apresentados em valores numéricos, para serem melhor discutidos.

A Tabela 1 apresenta os resultados para a análise do grupo dos animais, considerando tanto a totalidade das turmas investigadas, como individualmente por ano de ensino. Para a totalidade, foi tomada como análise os dezesseis grupos que construíram seus sistemas de classificação; enquanto que para cada ano, obtiveram-se apenas quatro grupos para análise.

É importante destacar que o número de grupos não se refere ao somatório das subcategorias e sim à identificação das mesmas estarem ou não presentes em cada um dos cartazes avaliados, para os grupos formados ( $\mathrm{N}^{\circ} \mathrm{de} \mathrm{Gr}$ ). Desta forma, o somatório pode ser superior ao número de grupos, uma vez que mais de uma subcategoria poderia estar presente em um mesmo cartaz analisado.

Os resultados mostram que as crianças identificaram três situações possíveis referentes ao agrupamento dos animais: reconhecimento, embora restrito de ambientes (terrestres, aquáticos e aéreos); separação por táxons; e, classificação por grupos por semelhanças e diferenças quanto às características observáveis. Buscando compreender se estas categorias se comportavam diferentemente entre os anos de ensino, de modo a verificar se nos anos finais há alguma mudança conceitual em relação à classificação, os resultados foram analisados também por anos de ensino.

Em relação à classificação por habitats (ambientes), pode-se verificar que foram identificados como terrestres, aquáticos e aéreos. É oportuno destacar que alunos de segundos e terceiros anos, não se contentaram em classificar apenas quanto ao habitat, como apresentado inclusive na maior parte de livros didáticos disponíveis para anos iniciais. Ou seja, além de classificarem os animais de acordo com o ambiente terrestre, sentiram a necessidade de subclassificar também, de acordo com a forma que estes animais se deslocam no ambiente terrestre; ou seja, se pulam, se andam, rastejam, ou sobem em árvores. Com a idade, esta preocupação parece diminuir e não detalham tais observações. 
Tabela 1 - Resultados para as categorias e subcategorias que emergiram da análise dos dezesseis cartazes (grupos), sobre a classificação biológica - animais, elaborado pelos alunos de anos iniciais.

\begin{tabular}{|c|c|c|c|c|c|c|c|c|}
\hline \multirow{3}{*}{ 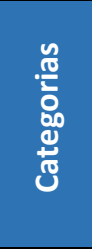 } & \multirow{3}{*}{$\begin{array}{c}\mathbf{N}^{0} \\
\text { de } \\
\text { Grupos }\end{array}$} & \multirow{3}{*}{\multicolumn{2}{|c|}{ Subcategorias }} & \multicolumn{5}{|c|}{$\begin{array}{l}\text { Número de grupos em que apresentaram } \\
\text { os dados } \\
\text { (4 grupos para cada ano) }\end{array}$} \\
\hline & & & & \multirow[t]{2}{*}{ Total } & \multicolumn{4}{|c|}{ Anos de ensino } \\
\hline & & & & & $2^{0}$ & $3^{\circ}$ & $4^{\circ}$ & $5^{\circ}$ \\
\hline \multirow{6}{*}{ 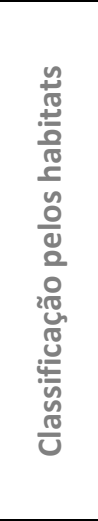 } & \multirow{6}{*}{11} & \multirow{3}{*}{$\begin{array}{l}\text { Terr } \\
\text { estr } \\
\text { e }\end{array}$} & Pulam & 4 & 3 & 1 & -- & -- \\
\hline & & & $\begin{array}{l}\text { Caminh } \\
\text { am/ } \\
\text { andam }\end{array}$ & 6 & 1 & 1 & 2 & 2 \\
\hline & & & $\begin{array}{c}\text { Rasteja } \\
\text { m }\end{array}$ & 4 & 2 & 2 & -- & -- \\
\hline & & \multicolumn{2}{|c|}{$\begin{array}{c}\text { Aquático/nada } \\
\mathrm{m}\end{array}$} & 10 & 4 & 1 & 3 & 2 \\
\hline & & \multicolumn{2}{|c|}{$\begin{array}{c}\text { Voam/têm } \\
\text { asas/aéreos }\end{array}$} & 8 & 4 & 2 & 1 & 1 \\
\hline & & \multicolumn{2}{|c|}{$\begin{array}{l}\text { Vivem em } \\
\text { árvores }\end{array}$} & 1 & 1 & -- & -- & -- \\
\hline \multirow{8}{*}{ 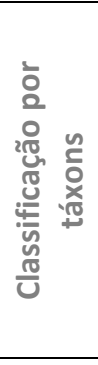 } & \multirow{8}{*}{9} & \multicolumn{2}{|c|}{ Insetos } & 5 & 2 & -- & 2 & 1 \\
\hline & & \multicolumn{2}{|c|}{ Répteis } & 5 & 1 & -- & 2 & 2 \\
\hline & & \multicolumn{2}{|c|}{ Invertebrados } & 4 & -- & 1 & 1 & 2 \\
\hline & & \multicolumn{2}{|c|}{ Anfíbios } & 3 & 1 & -- & 1 & 2 \\
\hline & & \multicolumn{2}{|c|}{ Mamíferos } & 3 & 1 & -- & 1 & 1 \\
\hline & & \multicolumn{2}{|c|}{ Vertebrados } & 3 & -- & 1 & 1 & 1 \\
\hline & & \multicolumn{2}{|c|}{ Peixes } & 2 & -- & -- & 1 & 1 \\
\hline & & \multicolumn{2}{|c|}{ Aves/pássaros } & 2 & -- & -- & 2 & 2 \\
\hline \multirow{6}{*}{ 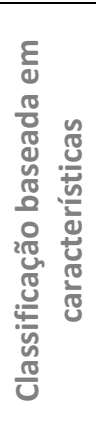 } & \multirow{6}{*}{8} & \multicolumn{2}{|c|}{$\begin{array}{c}\begin{array}{c}\text { Perigosos/ven } \\
\text { enosos }\end{array} \\
\end{array}$} & 2 & 1 & -- & 1 & -- \\
\hline & & \multicolumn{2}{|c|}{ Tem pelos } & 2 & -- & 1 & 1 & -- \\
\hline & & \multicolumn{2}{|c|}{$\begin{array}{l}\text { Serve de } \\
\text { alimento }\end{array}$} & 1 & -- & 1 & -- & -- \\
\hline & & \multicolumn{2}{|c|}{$\begin{array}{l}\text { Não serve de } \\
\text { alimento }\end{array}$} & 1 & -- & 1 & -- & -- \\
\hline & & \multicolumn{2}{|c|}{ Grudentos } & 1 & 1 & -- & -- & -- \\
\hline & & \multicolumn{2}{|c|}{$\begin{array}{c}\text { Com mais de } 4 \\
\text { patas }\end{array}$} & 1 & -- & -- & -- & -- \\
\hline
\end{tabular}

Fonte: Autoria própria (2019).

Ao pensarmos que uma das habilidades científicas a serem desenvolvidas nos anos iniciais está associada à capacidade e desenvolvimento de observação do mundo a sua volta e a proposição de perguntas (BRASIL, 2017), esperava-se que esta habilidade pudesse ser cada vez mais explorada, para que desenvolvesse no aluno a capacidade de ampliar suas potencialidades de observação ao longo dos anos escolares. No entanto, o que se verificou é que a medida que os anos avançaram, o conteúdo sistematizado já apresentado na escola, foi utilizado como uma forma de classificar de forma mais generalista do que nos primeiros anos, parecendo que a classificação, além de mais simplista, revelou aspectos de memorização geral de conceitos amplos e memorizados, como o caso de basear a proposta de classificação em hábitos terrestres, aquáticos e aéreos, tais como mostram os livros didáticos nos anos inicias. 
Estes resultados estão em consonância com o trabalho de Leonardi et al.. (2018), que afirmam em seus estudos realizados com crianças de anos iniciais que a classificação biológica animal é apresentada quase que exclusivamente, a partir da exploração do habitat (classificação dos animais quanto ao ambiente em que vivem, aéreos, terrestres e aquáticos) e ainda com base nos hábitos alimentares.

Também se verificou que o sistema de classificação biológica dos animais, nos primeiros anos foi reducionista quanto à possibilidade de ocupar vários nichos ambientais. Os alunos não reconheceram que os animais poderiam pertencer a mais de um ambiente ao mesmo tempo; ou seja, afirmaram que estes seres se deslocam só em solo ou eram capazes de voar ou ainda eram aquáticos. Os animais podem ter acesso a vários ambientes, o que não foi levado em consideração neste processo de discussão na sala de aula, mostrando-se bastante restritivo. Também se observou que no quarto e quinto ano, usaram os termos terrestres, aquáticos e aéreos, enquanto que nos segundos e terceiros anos, estes termos foram mais explicativos que conceituais. Por exemplo, na citação de um aluno "os animais têm asas e voam".

Ao observar os resultados ao longo dos anos de ensino, verificou-se que a classificação por habitat diminuiu com o avanço dos anos de escolaridade, em contrapartida, a classificação pelos táxons, foi significantemente superior no quarto e quinto ano. Alunos de segundos e terceiros anos, embora também propusessem classificação por táxons, a classificação feita foi baseada apenas em alguns grupos ou na divisão entre invertebrados e vertebrados. Já no quarto e quinto ano, todos os táxons passaram a ser representados. Os dados encontrados na Tabela 1, mostram ainda que, alunos de segundos e terceiros anos também evidenciaram mais as características observáveis do que os alunos maiores, tendo sido representadas por eles características destes animais, de forma mais significativa.

Constatou-se que as respostas apresentaram conceitos muito superficiais, simplistas e generalistas, e a medida que os anos avançam, as classificações apenas se mostraram mais memorísticas e menos observacionais, podendo os resultados preocupar no sentido de que os estudantes parecem apenas quererem enquadrá-los em um táxon específico sem fornecer maiores detalhes. A habilidade de observação, que foi evidenciada nos alunos de segundos e terceiros anos, ao invés de ampliada, passou a ser menor, quando comparada ao quarto e quinto ano.

Pacheco (2015) afirma que o caráter memorístico do ensino de Ciências baseia nos livros didáticos, que tratam dos seres vivos, se assemelhando a uma enciclopédia onde esses são catalogados em seus grupos, cada um com suas características sem levar em consideração as diferenças e as semelhanças.

Rosa e Mohr (2010) afirmam que os livros didáticos acabam por abordar os seres vivos limitando-os à descrição fisiológica e morfológica, sem abordar, por exemplo, seu papel no habitat. De fato, esta limitação esteve presente nesta análise, uma vez que apesar dos alunos terem elaborado um sistema de classificação, pode-se observar que se tratou de um sistema simplório, não apresentando subdivisões. Os alunos parecem se limitar ao que de fato é ensinado em livros didáticos de forma bastante restritiva nos anos iniciais, o que se tornou ainda mais evidente nos resultados para o quarto e quinto ano. 
Güllich, Emmel e Pansera-de-Araújo (2008) em um estudo sobre a análise de livros didáticos de Ciências para anos inicias, identificaram um conteúdo distorcido, reproducionista, generalizador e simplificador dos assuntos científicos, que geram um ensino em Ciências com sérios déficit na formação dos estudantes. Também constataram o uso de vocabulário infantilizado nos livros didáticos, o que segundo os autores não contribui para atrair a atenção deles, e nos dias de hoje, muitas crianças entre 7 e 10 anos de idade podem rejeitar este tipo de escrita, classificando esta como retrógrada e ultrapassada. Os autores também relatam que os livros didáticos muitas vezes apenas enfatizam o que eles chamam de "princípio da simplificação", onde os seres vivos apenas crescem, reproduzem-se e morrem. Uma visão utilitarista ou errônea dos animais, pois, por exemplo, apresenta as abelhas como sendo criadas para obter mel, cera e geleia real e muitos insetos como prejudiciais aos seres humanos, trazendo muitos problemas, pois contaminam o ambiente e podem afetar a saúde das pessoas. Ainda há discriminação de bactérias, citadas como prejudiciais à saúde de outros seres vivos, provocando doenças e até a morte.

Os resultados ainda mostraram que os alunos possuem dificuldade em compreender o grupo de insetos como invertebrados uma vez que não relacionavam um ao outro; isto é, os insetos foram colocados em um grupo separadamente dos invertebrados. Neste, inseriram por exemplo, minhoca e caracol, mas não inseriram os insetos, como se este fossem um grupo adicional. Os alunos demonstraram ainda confusão em relação a estes grupos taxonômicos. Os primeiros e segundos anos tiveram maior dificuldade para esta proposição. Já o quarto e quinto ano, citaram todos os táxons pertencentes aos vertebrados e tiveram menor dificuldade em inserir os insetos ao grupo dos invertebrados. Amaral e Medeiros (2015) afirmam em seus estudos que os alunos confundem constantemente os insetos com outros invertebrados, e até mesmo com vertebrados.

Por fim, classificaram de acordo com características que podem ser observáveis, entre elas a que teve maior destaque foi o fato de serem considerados perigosos e possuírem pelos. É interessante ressaltar a classificação realizada quanto ao fato de um organismo vivo servir ou não de alimento, sendo que apenas foi levado em consideração se esta refreia-se à alimentação humana. Os alunos não demonstram compreensão da importância ecológica de cada espécie.

Sobre isto, a discriminação também é relatada nos livros didáticos e descrita por Güllich (2004) como uma marginalização ou rejeição dos demais seres vivos em relação ao ser humano, sendo que todos os outros seres vivos ficam à mercê de descarte como se fossem inúteis e sem importância no contexto da vida no planeta. Schwertner (2000) corrobora afirmando que a abordagem dos seres vivos nas aulas de Ciências normalmente é planejada a partir de livros didáticos, dessa forma, as aulas não escapam das visões que esses materiais fazem da natureza, entre elas a antropocêntrica. Tal resultado também foi encontrado no momento em que os alunos propuseram um sistema de classificação baseado em, "servir ou não servir de alimento para os humanos". Esta visão antropocêntrica de a natureza estar ao nosso dispor para nos servir, esteve presente tanto na classificação das imagens de animais, como na classificação dos vegetais (Tabela 2). 
De fato, as visões da natureza que ainda permeiam o currículo escolar se mostram antropocêntricas e utilitaristas, onde os animais são apresentados segundo sua utilidade e nocividade aos seres humanos (SANTOS, 2000).

Ferreira et al. (2018) afirmam que é fundamental desenvolver na escola uma discussão ampliada a respeito. De nada adianta compreender sobre seres vivos, sem estabelecer uma relação intrínseca com a complexidade do mundo vivo e da necessidade de relações harmoniosas entre todos os elementos do ambiente.

A Tabela 2 apresenta os resultados para a análise dos dezesseis cartazes (grupos) sobre a classificação biológica - Plantas, construídos pelos alunos de anos iniciais.

Tabela 2 - Resultados para as categorias e subcategorias que emergiram da análise dos dezesseis cartazes (grupos), sobre a classificação biológica - Plantas, elaborado pelos alunos de anos iniciais

\begin{tabular}{|c|c|c|c|c|c|c|c|}
\hline \multirow[t]{2}{*}{ Categorias } & \multirow[t]{2}{*}{$\begin{array}{l}\mathbf{N}^{\circ} \text { de } \\
\text { grupos }\end{array}$} & \multirow[t]{2}{*}{ Subcategorias } & \multicolumn{5}{|c|}{$\begin{array}{l}\text { Número de grupos em que } \\
\text { apresentaram os dados } \\
\text { (4 grupos para cada ano) }\end{array}$} \\
\hline & & & Total & $\begin{array}{l}2^{\circ} \\
\text { Ano }\end{array}$ & $\begin{array}{l}3^{\circ} \\
\text { Ano }\end{array}$ & $\begin{array}{l}4^{\circ} \\
\text { Ano }\end{array}$ & $\begin{array}{l}5^{\circ} \\
\text { Ano }\end{array}$ \\
\hline \multirow{4}{*}{$\begin{array}{l}\text { Classificação } \\
\text { por estrutura } \\
\text { de plantas }\end{array}$} & \multirow[t]{4}{*}{14} & Plantas & 13 & 4 & 3 & 3 & 3 \\
\hline & & Árvores & 6 & 2 & -- & 1 & 3 \\
\hline & & $\begin{array}{l}\text { Plantas com } \\
\text { flores }\end{array}$ & 6 & 2 & & 1 & 3 \\
\hline & & $\begin{array}{c}\text { Plantas com } \\
\text { frutos }\end{array}$ & 1 & 1 & -- & -- & -- \\
\hline \multirow[t]{2}{*}{$\begin{array}{l}\text { Classificação } \\
\text { por visão } \\
\text { utilitarista }\end{array}$} & \multirow[t]{2}{*}{10} & $\begin{array}{c}\text { Para } \\
\text { alimentação }\end{array}$ & 10 & 2 & 2 & 3 & 3 \\
\hline & & $\begin{array}{c}\text { Para } \\
\text { decoração }\end{array}$ & 1 & -- & -- & -- & 1 \\
\hline \multirow[t]{3}{*}{$\begin{array}{l}\text { Classificação } \\
\text { por hábitos }\end{array}$} & \multirow[t]{3}{*}{2} & $\begin{array}{c}\text { Plantas } \\
\text { terrestres }\end{array}$ & 2 & -- & 1 & 1 & -- \\
\hline & & $\begin{array}{c}\text { Plantas } \\
\text { aquáticas }\end{array}$ & 2 & -- & 1 & 1 & -- \\
\hline & & Plantas aéreas & 1 & -- & -- & 1 & -- \\
\hline
\end{tabular}

Fonte: Autoria própria (2019).

A Tabela 2 evidencia como a classificação de plantas para cada categoria foi elaborada pelos alunos e constatou-se que os participantes se detiveram principalmente aos aspectos estruturais e à visão utilitarista, em especial ao papel destes seres vivos na alimentação humana.

Segundo Silva, Lavagnini e Oliveira (2009), esta visão utilitarista antropocêntrica é estimulada desde os anos iniciais do ensino fundamental, mantendo-se constante até o final do ensino médio. Nas séries iniciais, o estudo dos seres vivos segue o critério de classificação segundo sua importância ou utilização pelo ser humano. Este olhar utilitarista sobre as plantas, também foi verificado no trabalho desenvolvido por Kinoshita et al. (2006) em duas turmas de 6a série de escolas públicas de Campinas -SP. 
Tais resultados também foram encontrados nessa pesquisa, uma vez que a maioria dos grupos de estudantes apontaram como critério de classificação biológica das plantas a visão utilitarista no que se refere à alimentação humana e para fins decorativos. A estrutura das plantas pouco foi explorada pelos participantes senão pelos fatos de ter aparência de planta em si.

Da mesma forma que os resultados já discutidos em relação ao grupo de animais, os pesquisadores Leonardi et al. (2018) também evidenciaram em sua investigação sobre concepções de alunos de anos inicias sobre os seres vivos, que a classificação vegetal também é desenvolvida a partir da exploração do ambiente em que as plantas são encontradas e em relação a sua utilidade para o homem.

Os resultados desta pesquisa foram semelhantes aos encontrados neste trabalho. Porém, os ambientes foram levados em consideração de forma menos significativa que os animais. A classificação estabelecida pelos alunos, mostrou-se superficial, e se deu em termos estruturais, reconhecendo as imagens como plantas, mas sem especificar em maiores detalhes as partes vegetais que compõem estes seres.

Bitencourt et al. (2009) corroboram, afirmando que uma das concepções utilizada pelos estudantes para conceituar as plantas é o conceito utilitarista das mesmas, tais como: terapêutica, alimentícia, cosmética, industriais e ornamentais, o que também foi evidenciado na análise dos resultados desta investigação.

Martins e Guimarães (2002) destacam que a abordagem sobre os vegetais se inicia com a classificação das plantas (aéreas, aquáticas e terrestres, com flores e sem flores), suas partes (raiz, caule, folha, flores, frutos) e termina com a ênfase na sua utilização "só" para o homem (comer, enfeitar nossas casas, fabricar móveis e casas, fazer remédios e chás, fabricar tecidos, etc.). Os animais também são submetidos ao domínio humano: "servem" para alimentação, vestuário, transporte, proteção, lazer e para serem observados, dentre outras.

Nesta perspectiva antropocêntrica, a natureza é um objeto a ser usado e consumido, com seus recursos minerais, vegetais e animais, atendendo a demanda e a voracidade do ser humano. Para um ensino significativo, é necessário desenvolver na escola uma discussão relevante a respeito. Apenas compreender os seres vivos sem estabelecer uma relação com o mundo vivo e compreender seu valor intrínseco, não é significativo. Há a necessidade de estabelecer relações harmoniosas entre todos os seres vivos e o ambiente (FERREIRA et al., 2018).

Para Lopes (2005), o diálogo com as crianças sobre estes assuntos poderá acelerar o processo de reconquista das relações harmoniosas entre os humanos e o mundo mineral, vegetal e animal, valorizando sua importância para a preservação do ecossistema.

Diante destes resultados, é importante destacar que já nos anos iniciais a criança se depara com o conhecimento científico e sua compreensão dependerá da concepção de Ciência e de Educação que baliza a prática pedagógica de seus professores. Infelizmente, para muitos docentes, o ensino de Ciências naturais é desenvolvido de forma propedêutica (FERREIRA et al., 2018), sem levar em consideração o desenvolvimento das habilidades científicas. 
Portanto, o ensino de Ciências nos anos iniciais deve possibilitar questionamentos, situações problemáticas que levem às crianças a construírem seus primeiros significados importantes do mundo, favorecendo, além da construção de conteúdo conceitual (conceitos e fatos), o desenvolvimento de atitudes científicas, de habilidades e competências, que só podem ser conseguidas por meio de uma orientação adequada e consciente (GOLDSCHMIDT, 2012). Estas possibilitam ampliar a visão de mundo, além de desenvolver a capacidade da observação do mundo que o cerca e a prática da autonomia.

Rodrigues e Rodrigues (2018) discorrem sobre a importância de propiciar, já no início dos anos escolares, uma educação que permita aos alunos desenvolver autonomia para pensar e agir em situações do seu cotidiano, especialmente aquelas que envolvam conhecimentos de ciências.

Tabela 3 - Resultados para as categorias e subcategorias que emergiram da análise dos dezesseis cartazes (grupos), sobre a classificação biológica - Organismos Menores, elaborada pelos alunos de anos iniciais

\begin{tabular}{|l|c|c|c|c|c|c|}
\hline \multirow{2}{*}{ Categorias } & \multirow{2}{*}{$\begin{array}{c}\mathbf{N}^{\mathbf{0}} \text { de } \\
\text { grupos }\end{array}$} & \multicolumn{5}{|c|}{$\begin{array}{c}\text { Número de grupos em que apresentaram os } \\
\text { dados (4 grupos para cada ano) }\end{array}$} \\
\cline { 3 - 8 } & & Total & $\mathbf{2}^{\circ}$ Ano & $\mathbf{3}^{\circ}$ Ano & $\mathbf{4}^{\circ}$ Ano & $\mathbf{5}^{\circ}$ Ano \\
\hline Classificação por tipos & 3 & 4 & 1 & -- & 2 & 1 \\
\hline Classificação por tamanho & 8 & 9 & 3 & 3 & 2 & 1 \\
\hline Classificação por riscos & 7 & 7 & 2 & 3 & 2 & 2 \\
\hline
\end{tabular}

Fonte: Autoria própria (2019).

Ao analisar a Tabelas 3 pode-se observar como os alunos dos anos iniciais classificaram os microrganismos e como esta classificação variou nos distintos níveis de ensino. Os resultados indicam que os participantes reconhecem a dimensão de tamanho desses seres vivos, surgindo grupos como "não podemos ver" e "são muito pequenos", entre outros. O termo microscópio é significativamente reconhecido a partir dos avanços dos anos de ensino, tendo um acréscimo de percentuais, de forma gradual do segundo ao quinto ano.

Os estudos de Byrne e Sharp (2006) apontam que os alunos de anos inicias tem noção apenas que esses pequenos seres existem, que são invisíveis a olho nu e que possuem pouco conhecimento sobre as características adicionais destes. Bernardi et al. (2019) em uma investigação sobre as concepções de alunos de anos iniciais acerca dos microrganismos apontaram que os alunos possuem uma visão reducionista acerca desses seres vivos, relacionando-os à sujeira e às doenças, o que, em termos de processo de ensino e aprendizagem, pode gerar obstáculos que dificultem a compreensão dos alunos sobre a grande variedade de microrganismos no planeta e, que embora alguns tragam malefícios, a grande maioria deles é benéfica.

Desse modo, tais discussões se tornam relevantes, pois a medida que classificam inicialmente os seres em apenas três grupos, como animais, plantas e organismos menores, os alunos demonstram conseguir observar o mundo e a diversidade. Se oportunizarmos em sala de aula, discussões, vivências e experiências que possam aproximar estes alunos da diversidade biológica existente, os estudantes poderão compreender melhor a importância destes seres vivos menores na manutenção da vida, nas aplicações biotecnológicas nas 
mais diversas áreas, como na indústria alimentícia e farmacêutica por exemplo, contribuindo para que se possa desmistificar a visão reducionista, que segundo Vila Boas e Moreira (2012) é apresentada muitas vezes nos livros didáticos, relacionando os microrganismos apenas com as doenças humanas.

Em relação à última categoria, os discentes classificaram os microrganismos quanto ao tipo, e ao analisar a forma como subdividiram os mesmos, observou-se que os associaram a germes, grupos de vírus e às bactérias, adicionando todos os representantes de imagens de vírus, bactérias, fungos e protozoários a este único grupo. Os participantes mostraram o não reconhecimento de grupos distintos de microrganismos e tiveram dificuldade em agrupá-los.

Trabalhar o conteúdo de microbiologia com os alunos dos anos iniciais implica em algumas dificuldades, pois é um conteúdo demasiadamente abstrato para eles e também para os docentes. Os participantes não conseguiram relacionar os microrganismos ao seu cotidiano, não compreendendo a importância dos mesmos para a manutenção do equilíbrio ecológico.

\section{CONSIDERAÇÕES FINAIS}

Consideramos que o ensino de ciências nos anos iniciais do ensino fundamental deve ser contextualizado com as concepções e experiências prévias dos estudantes. A classificação e sistematização são processos naturais para a formação de conceitos e cognição. Classificar os organismos vivos é parte da relação construída a partir já de habilidades científicas presentes na criança, como a curiosidade, a observação, a elaboração de hipóteses e a construção de modelos, sendo estas, importantes para serem exploradas e ampliadas em sala de aula.

À medida que o professor apresenta o conteúdo de classificação dos organismos vivos, sem oportunizar aos estudantes o desenvolvimento dessas habilidades, o ensino passa a apenas reproduzir os conteúdos presentes nos livros didáticos, impossibilitando a construção da ciência e de uma maior compreensão de mundo. Igualmente é importante valorizar as diversas formas de se interpretar e organizar os seres vivos, pois à medida que se oportuniza aos alunos escolherem um método ou outro, eles além de desenvolverem a arguição, praticam a autonomia de pensamento.

Os alunos mostraram uma classificação simplificada, e reducionista, limitando-se principalmente aos ambientes onde estes organismos vivos podem ser encontrados. Constatou-se que os menores (primeiro ao terceiro ano) desenvolveram mais a observação que os alunos maiores. O quarto e quinto ano, mostraram se deter mais ao conteúdo presente no livro didático, de forma memorística, classificando em táxons, sem se permitir a elaboração de novos modelos. Os alunos não elucidaram maiores detalhamentos das interações ambientais possíveis e da possibilidade da existência de diversificação de nichos para os organismos biológicos. Este equívoco aparentemente pequeno pode gerar erros consideráveis de interpretação e contribuir para obstáculos de aprendizagem mais tarde.

Assim, espera-se que esse artigo possa servir para indagar os professores dos anos iniciais sobre formas de desenvolvimento do conteúdo classificação dos 
seres vivos, a fim de promover aulas de Ciências mais interessantes tanto para os discentes como também para os docentes, e que busquem explorar as observações dos alunos, levantando em consideração suas concepções do mundo, associando-as aos conhecimentos científicos, baseadas na exploração, observação, comparação, proposição de modelos, arguição e relatos, além de outras habilidades, que possam contribuir para um ensino mais eficaz. 


\title{
Classification of living beings by elementary school students: a proposal for the development of scientific skills
}

\begin{abstract}
The article presents a pedagogical experience developed with students from the early years of elementary school of a public school in the city of Palmeira das Missões, RS, during the process of teaching the biological classification of living beings that aimed to highlight the knowledge. students' daily life on the form of organization and classification of the diversity of living organisms, allowing to evaluate and discuss the differences in relation to biological classification, without, however, proposing the exclusion of one knowledge because it considers the other the correct one. In addition, provide opportunities for students to develop scientific skills associated with observing, organizing, classifying, proposing models, arguing and reporting orally. The research had as investigative instrument the construction of posters, presenting a biological classification system from the observation of 36 images (photographic) containing different specimens of animals, plants, fungi, viruses, bacteria and protozoa. Thus, the students were observed in each group by one of the researchers and in addition to organizing the classification system, should establish criteria for them. In all, sixteen groups were formed, which organized sixteen rating posters, these were collected and analyzed. The results showed that the students classified the animals according to their environment, taxon and observable characteristics. Habitat classification was found to decrease with advancing school years, with less emphasis on observation. As for plants, it was observed that most students have an anthropocentric utilitarian view, especially the role of these organisms in human food. Regarding microorganisms, it was noted that students have a reductionist and often erroneous view of these beings, classifying them as minor causes of disease. Comparing the years of education, it was found that the students of the first years (first, second and third) showed better development of observation and as they get older, the classification was more memoristic, and based on the rates and classifications present in Didatic books. These results show that developing students' scientific skills is very important.
\end{abstract}

KEYWORDS: Systematics. Science teaching. Previous concepts. Elementary School. 


\section{REFERÊNCIAS}

ALVARENGA, J. P. de; et al. Ciências naturais no dia-a-dia. Manual do professor. 1. ed. 6a série. Curitiba: Positivo, 2004.

AMARAL, K.O.; MEDEIROS, M.A. Análise das concepções de estudantes do ensino fundamental sobre insetos, por meio da metodologia do discurso do sujeito coletivo. Brazilian Geographical Journal: Geosciences and Humanities research medium, v. 6, n.1, p. 156-180, 2015.

AMORIM, D. S.; et al. Diversidade biológica e evolução: uma nova concepção para o ensino de zoologia e botânica no 2 ㅇ grau. p. 38-45. In: BARBIERI, M. (Org.). A construção do conhecimento do professor. Uma experiência de integração de professores do ensino fundamental e médio da Rede Pública à universidade. Ribeirão Preto: Holos, 2002.

AMORIM, D. S.; et al. Diversidade biológica e evolução: Uma nova concepção para o ensino. p. 9-17. In: BARBIERI, M. (Org.). Aulas de Ciências. Projeto LEC-PEC de Ensino de Ciências. Ribeirão Preto: Holos, 1999.

AMORIM, D.S. Paradigmas pré-evolucionistas, espécies ancestrais e o ensino de zoologia e botânica. Ciência \& Ambiente, Santa Maria, v. 36, p. 125-150, 2008.

BAPTISTA, G. C. S. Importância da demarcação de saberes no ensino de Ciências para sociedades tradicionais. Ciência \& Educação (Bauru), Bauru, v.16, n. 3, p. 679-694, 2010.

BARDIN, L. Análise de conteúdo. São Paulo: Edições 70, 2011.

BERNARDI, G.; et al. Concepções prévias dos alunos dos anos iniciais sobre microrganismos. Revista Ciências e Ideias, vol. 10, n. 1, janeiro/abril. 2019. Disponível em:https://revistascientificas.ifrj.edu.br/revista/index.php/reci/article/view/974. Acesso em: 04 out. 2018.

BITENCOURT, I. M.; et al. As plantas na percepção de estudantes do ensino fundamental no município de Jaquié - Ba. In Encontro Nacional Pesquisa em Educação em Ciências, 7. Florianópolis. 2009. Anais... Florianópolis: EDUFSC. 2009 .

BRASIL. Base Nacional Comum Curricular: Educação Infantil e Ensino Fundamental. Brasília: MEC/Secretaria de Educação Básica, 2017.

BYRNE, J.; SHARP, J. Children's ideas about micro-organisms. School Science Review, London, v. 88, n. 322, p. 71-79, 2006.

CARVALHO. A. M. P; et al. Ciências no ensino fundamental: o conhecimento físico. São Paulo: Scipione, 1998. 
FERREIRA, S. A.; et al. Atividades metacognitivas como facilitadoras na aprendizagem sobre seres vivos nos anos iniciais. Amazônia: Revista de Educação em Ciências e Matemáticas, v. 14, n. 29, p. 43-62, jul. 2018. Disponível em: https://periodicos.ufpa.br/index.php/revistaamazonia/article/view/5374. Acesso em: 10 out. 2019.

GASPARIN, J. L. Uma Didática para a Pedagogia Histórico-Crítica. 3a Edição. Campinas, SP: Autores Associados, 2005.

GOLDSCHMIDT. A. I. $O$ ensino de Ciências nos anos iniciais: sinalizando possibilidades de mudanças. 2012. Tese (Doutorado em Educação em Ciências) Universidade Federal de Santa Maria: Santa Maria, 2012. Disponível em: https://repositorio.ufsm.br/handle/1/3525. Acesso em: 02 out.2019.

GÜLLICH, R. I. da C. Desconstruindo a imagem do livro didático no ensino de Ciências. Revista SETREM. Três de Maio, v. 4, n. 3, p. 43 - 51, jan. 2004

GÜLLICH, R. I. C.; EMMEL, R. e PANSERA-DE-ARAÚJO, M. C. Interfaces da pesquisa sobre o livro didático de Ciências. In: VII Encontro Nacional de Pesquisa em Educação em Ciências. Anais... Florianópolis, 8 de novembro de 2008.

KINOSHITA, L. S.; et al. A botânica no ensino básico: relatos de uma experiência transformadora. São Carlos: RiMa, 2006.

KRASILCHIK, M. Prática de Ensino de Biologia. São Paulo: Universidade de São Paulo, 4a ed. 2011.

LAKOFF, G. Women, Fire, and Dangerous Things. What Categories Reveal about the Mind, Chicago: The University of Chicago Press. 1987.

LEITE, L.; ESTEVES, E. Análise crítica de actividades laboratoriais: Um estudo envolvendo estudantes de graduação. Revista Electrónica de Enseñanza de las Ciencias. v. 4, no 1. Braga, Portugal: 2005.

LEONARDI, A. F.; et al. Análise das concepções alternativas de alunos dos anos iniciais acerca dos seres vivos. Revista Educere Et Educare, vol. 13, n. 30, nov./dez. 2018. Disponível em: http://e-

revista.unioeste.br/index.php/educereeteducare/issue/view/931. Acesso em: 10 ago. 2019.

LOPES, M. H. As Florestas, os Rios, os Mares, Eu e os Animais. In: LOPES, M. H. (org) A Criança descobrindo, interpretando e agindo sobre o Mundo. Brasília: UNESCO, Banco Mundial, Fundação Maurício Sirotsky Sobrinho, Série Fundo do Milênio para a Primeira Infância Cadernos Pedagógicos, 2005. 8 p.

MARTINS, E. F.; GUIMARÃES, G. M. A. As concepções de natureza nos livros didáticos de Ciências the conceptions of nature of didactic books of sciences. Revista Ensaio. Belo Horizonte, v.04, n.02, p.101-114, dezembro, 2002. 
MAYR, E. Desenvolvimento biológico: diversidade, evolução e herança. Tradução Ivo Martinazzo - Brasilia, DF: Editora Universidade de Brasília, 1998 [1982]

MAYR, E. Isto é biologia: a ciência do mundo vivo. Tradução: Claudio Angelo, São Paulo, Companhia da Letras, 2008.

PABÓN-MORA, N.; GONZÁLEZ, F. A classificação biológica: de espécies a genes. In: ABRANTES, P.C. (Org.) Filosofia da biologia. Porto Alegre: Artmed, 2011. P.123-144

PACHECO, R. S. Análise do conteúdo de mamíferos em livros didáticos do ensino básico em Florianópolis. 2015. Trabalho de Conclusão de Curso (Bacharelado em Ciências Biológicas). Universidade Federal de Santa Catarina, Florianópolis, 2015.

RODRIGUES, C. S. C.; RODRIGUES, M. A. Refletindo sobre o ensino de ciências com professores dos anos iniciais por meio de uma sequência de ensino investigativo. ACTIO, Curitiba, v. 3, n. 2, p. 58-79, mai./ago. 2018. Disponível em: http://oaji.net/articles/2017/6441-1540491394.pdf. Acesso em: 10 out. 2019.

ROMA; V. N; MONTOKANE, M. T. Classificação biológica nos livros didáticos de biologia do ensino médio. In: VI ENPEC Encontro Nacional de Pesquisa em Educação em Ciências. Anais... Florianópolis, 2007.

ROSA, M. D. A.; MOHR, A. Os fungos na escola: análise dos conteúdos de Micologia em livros didáticos do Ensino Fundamental de Florianópolis.

Experiências em Ensino de Ciências, v. 5, n. 3, p. 95- 102, 2010.

SANTOS, C. M. D. e CALOR, A. R. Ensino de biologia evolutiva utilizando a estrutura conceitual da sistemática filogenética. Ciência \& Ensino, Campinas, v. 1, n.2, 2007.

SANTOS, E. S. M. A miopia sistêmica no atual modelo de ensino centrado no professor. In: Seminário em Administração. Anais... São Paulo. 2012, p. 1-14.

SANTOS, L. H. S. Biologia dentro e fora da escola. Porto Alegre: Mediação: 2000.

SCHWERTNER, C. F. Os bichos na natureza da sala de aula. In: SANTOS, L. H. S. (Org.). Biologia dentro e fora da escola: caderno de educação básica 6. ed. Porto Alegre: Editora Mediação, 2000. p. 25- 40.

SILVA, C. S. F.; LAVAGNINI, T. C.; OLIVEIRA, R. R. Concepções de alunos do $3^{\circ}$ ano do Ensino Médio de uma escola pública de Jaboticabal - SP a respeito de evolução biológica. In: Encontro Nacional De Pesquisa Em Educação Em Ciências. Anais... Florianópolis: EDUFSC, 2009.

SIMPSON, G. G. Princípios de Taxonomia Animal. Trad.: Fernando A. Ilharco. 2. ed. Lisboa, Portugal: Fundação Calouste Gulbenkian, 1971. Lavras, MG. Revista Brasileira de Ciência do Solo, v. 36, n. 1, p. 295-306, 2012. 
WAIZBORT, R. F. Cento e quarenta anos sem Darwin bastam: sobre espécies variedades e definições. Principia (UFSC), Florianópolis, v. 4, n. 1, p. 141-184, 2000.

WELKER, C. A. D. O estudo de bactérias e protistas no ensino médio: uma abordagem menos convencional. Experiências em Ensino de Ciências. v. 2, no 2, p. 69-75. Porto Alegre: 2007.

Recebido: 05 jul. 2019

Aprovado: 14 out. 2019

DOI: 10.3895/actio.v4n3.10325

Como citar:

GOLDSCHMIDT, A. I.; LEONARDI, A. F.; RANGEL, C.; BERNARDI, G.; SILVEIRA, M. DOS S.; FERREIRA

S. A. Classificação de seres vivos por alunos de anos iniciais do ensino fundamental: uma proposta de desenvolvimento de habilidades científicas. ACTIO, Curitiba, v. 4, n. 3, p. 110-130, set./dez. 2019. Disponível em: <https://periodicos.utfpr.edu.br/actio>. Acesso em: XXX

Correspondência:

Andréa Inês Goldschmidt

Rua Sete de Setembro, 587, Bairro Centro, Palmeira das Missões, RS, Brasil

Direito autoral: Este artigo está licenciado sob os termos da Licença Creative Commons-Atribuição 4.0 Internacional. 